\title{
Listado de Memorias de Título de Geografía Universidad de Chile 2005-2006 MEMORIAS DE TITULO 2005
}

Autor: Cerda M., Ignacio.

Titulo: Diagnostico ambiental de la isla Marinero Alejandro Selkirk, parque nacional archipiélago Juan Fernández, V Región de Valparaíso

Autor: Chávez Valdivia, Carolina.

Titulo: Amenazas naturales en media y baja montaña asociados al corredor de comercio Las leñas, VI Región del Libertador Bernardo O’Higgins.

Autor: Cornejo González, Betsy

Titulo: Evolución de la economía ganadera en la provincia de Ultima Esperanza, XII Región: posible alternativa de desarrollo productivo.

Autor: Herrera Osandón, Mariajosé.

Titulo: Geomorfología de la cuenca del Glaciar Chico, Campos de Hielo Sur, Chile Austral

Autor: Maldonado del Otero, Consuelo

Titulo: Análisis espacial de las enfermedades respiratorias en adultos mayores y su relación con el medio ambiente urbano.

Autor: Maldonado Rojo, Mauricio.

Titulo: Organización funcional y espacial de la salmonicultura: efectos socioeconómicos en la Isla Lemuy, Provincia de Chiloé.

Autor: Matute Willemsen, Juan

Titulo: Análisis de la degradación del bosque en las Islas Lemuy, Quehui y Quinchao, Archipiélago de Chiloé.

Autor: Muñoz Villablanca, Felipe Santiago.

Titulo: Análisis de la dinámica costera en ensenadas de Chile central: Litoral de Cachagua y Papudo.

Autor: Navarro Meneses, Marcia.

Titulo: Hacia un ordenamiento predial participativo y proposición de un modelo alternativo de producción: Comunidad indígena Juan Huentelen: Comuna Padre Las Casas provincia Cautín

Autor: Rocha Pérez, Rodrigo.

Titulo: Estructura agraria de la comunidad agrícola Alhuemilla-Las Palmas Comuna de Canela. IV Región.

Autor: Rodríguez Navarrete, Yuri.

Titulo: Cambios socio espaciales y morfológicos en una comuna de alto status social del gran Santiago : el caso de Vitacura 
Autor: Rojas Montecino, Patricio.

Titulo: La vitivinicultura y su proceso de expansión en ladera en el valle de Lontué, Región del Maule

Autor: Troncoso Araya, Tamara Rayen

Titulo: Propuesta de ordenamiento territorial estrategia en la Comuna de Sierra Gorda.

\section{MEMORIAS DE TÍTULO 2006}

Autor: Anabalón Alamos, Gerardo José.

Titulo: Impactos espaciales producidos por la proliferación de la fruticultura: Comuna de Petorca, V región de Valparaíso.

Autor: Avalos Pino, Pablo.

Titulo: Los impactos socio espaciales en las caletas de pescadores artesanales de la Comuna de Corral en el marco de la legislación pesquera promulgada entre los años 1990-2005.

Autor: Bastidas Quintanilla, María José.

Titulo: Degradación del bosque pluvial del sur de la Isla Grande de Chiloé, por una industria química. Comuna de Quellón.

Autor: Buscaglia Fuentealba, Aldo.

Titulo : Zonificación de las áreas naturales de uso público según impactos ambientales del uso recreativo : comuna de San José de Maipo, Región Metropolitana.

Autor: Carrasco Millan, Juan Eduardo.

Titulo: La desertificación en la comuna de Punitaqui: Jerarquización de espacios de intervención desde un enfoque antrópico.

Autor: Elgueta Astaburuaga, María Alejandra.

Titulo: Gran Santiago transformación del patrón espacial de localización del sector residencial de la elite.

Autor: Elmes Angulo, Max Eduardo.

Titulo: Análisis y evaluación de riesgos por movimientos en masa, inundación y sismicidad en el piedmont de la comuna de Puente Alto.

Autor: Fernández Torres, Roberto.

Titulo: Evaluación de procesos erosivos y su influencia sobre el corredor de comercio Las Leñas : VI región del Libertador Gral. Bernardo O’Higgins.

Autor: Gallardo Vicencio, Jaime Andrés.

Titulo : Expansión del límite urbano de la ciudad de Salamanca y los impactos derivados en su espacio agrícola.

Autor: Hormazábal Henríquez, Jazmine.

Titulo: Degradación espacial y temporal del bosque nativo, en el noreste de la Isla Grande de Chiloé, X Región. 
Autor: Ibáñez Browne, María de los Ángeles.

Titulo: Elementos territoriales para la valoración del patrimonio: Chiloé y sus festividades religiosas.

Autor: Marín Alfaro, Jorge.

Titulo: Clasificación territorial de potenciales áreas de sustentación para el proceso de modernización agrícola en la Comuna de Punitaqui.

Autor: Medina Rodríguez, Angélica.

Titulo: Alternativas de desarrollo rural sustentable para una comunidad agrícola tradicional en proceso de desertificación : El Divisadero, Comuna de Punitaqui, IV Región de Coquimbo.

Autor: Mondino Ramos, Ricardo Marcelo

Titulo: Actividades conflictivas en zonas residenciales de la Comuna de La Florida.

Autor: Mora Soto, Alejandra Isabel.

Titulo: Propuesta para èl desarrollo sustentable del parque nacional Torres del Paine en la estancia Cerro Paine.

Autor : Morales Constanzo, Mauricio F.

Titulo : Análisis de la degradación de la cobertura vegetacional nativa en la cuenca superior del Río Palena. Chiloé Continental.

Autor: Pradenas Gaete, Juan.

Titulo: Delimitación funcional del área metropolitana territorio de Santiago: un territorio en busca de gobierno.

Autor: Retamales Villa, Carol Macarena.

Titulo: Efectos socio espaciales derivados de la concentración de la población en Villorrios agrícolas en el contexto de la globalización : comuna de Sagrada Familia VII región del Maule.

Autor: Rugiero de Souza, Vanessa

Titulo: Suelos potencialmente aptos para revegetación o uso agrícola a partir de la utilización de biosólidos provenientes de las plantas de tratamiento de aguas servidas en la provincia de Chacabuco, Región Metropolitana

Autor: Sáez Seguel, Cecilia.

Titulo: Efectos geográficos de eventos catastróficos caso terremoto maremoto 22 mayo 1960 , Ancud.

Autor: Segovia Rocha, Alexis A.

Titulo: Análisis del crecimiento urbano por segundas residencias en el borde costero de dos comunas de la V Region : Zapallar y Papudo

Autor: Traverso González, Gianna Elisa.

Titulo: Historia y configuración socio-espacial del sector El Castillo, Comuna de La Pintana: Aproximación al ghetto en el estudio de la geografía social.

Autor: Troncoso Urquiza. Raúl.

Titulo: Efectos socio-espaciales derivados de la vitivinicultura: Caso Comuna de Casablanca V Región de Valparaíso. 
Autor: Uribe Cifuentes, Juan Pablo.

Titulo: Diagnóstico espacial de salud ambiental de las provincias de Cordillera, Chacabuco, Maipo, Melipilla y Talagante. Región Metropolitana.

Autor: Venegas Ordenes, Miguel A.

Titulo: Amenaza fluvial y viabilidad geográfica de un sistema de explotación de áridos para el manejo estructural de los cauces fluviales en el área de Valdivia de Paine, de la comuna de Buin.

Autor: Villarroel Rojas, Iván Patricio.

Titulo: Identificación y evaluación de espacios con potencial ganadero y su impacto socioespacial, en la comuna de Negrete, en el marco del acuerdo entre Chile y la Unión Europea. 